\title{
Template-Free Synthesis of Zinc Oxide Hollow Microspheres in Aqueous Solution at Low Temperature
}

\author{
Y. F. Zhu, D. H. Fan, and W. Z. Shen* \\ Laboratory of Condensed Matter Spectroscopy and Opto-Electronic Physics, Department of Physics, \\ Shanghai Jiao Tong University, 1954 Hua Shan Road, Shanghai 200030, People's Republic of China
}

Received: September 20, 2007

\begin{abstract}
A novel template-free hydrothermal method is developed to prepare large-scale $\mathrm{ZnO}$ hollow microspheres. The key strategy for the successful realization is that we employ a high concentration of trisodium citrate to control the nucleation and growth rate of $\mathrm{ZnO}$ crystal forming microspheres with core/shell structures and the proper $\mathrm{pH}$ of an alkaline solution to remove the cores generating hollow microspheres. The morphology, structure, and composition of the microspheres have been investigated with field-emission scanning electron microscopy and high-resolution transmission electron microscopy for the growth mechanism. A series of controlled experiments have also been carried out to better understand the formation mechanism of $\mathrm{ZnO}$ hollow microspheres and the function of reactants used in the experiments. The infrared absorption spectra indicate that annealing can lead to the decomposition of impurity groups in the as-prepared sample. Both room-temperature Raman and photoluminescence results demonstrate that the annealed $\mathrm{ZnO}$ microspheres are of good crystalline wurtzite structure with high optical quality.
\end{abstract}

\section{Introduction}

Zinc oxide $(\mathrm{ZnO})$, an important wide band gap $(3.37 \mathrm{eV})$ semiconductor, has the prospect of wide application in many fields because of its outstanding optical and electronic properties. Various $\mathrm{ZnO}$ nanostructures, including nanodots, nanorods, nanowires, nanotubes, nanopores, and so on, have been successfully fabricated by a variety of methods to further broaden its application. ${ }^{1-5}$ Recently, the synthesis of hollow micro- and nanospheres is also of great interest to material scientists, physicists, and chemists due to their potential applications in photonic crystals, catalysts, sensors, artificial cells, nanoscale chemical reactors, energy-storage media, drug-delivery carriers, etc. ${ }^{6-12} \mathrm{~A}$ number of hollow-structured materials, including silica, $\mathrm{Co}_{3} \mathrm{O}_{4}, \mathrm{Fe}_{3} \mathrm{O}_{4}$, and $\mathrm{CuS}$, have been fabricated by using sacrificial templates. ${ }^{10}$ Hollow $\mathrm{ZnO}$ structures have also been successfully synthesized. ${ }^{11-15}$

So far, there are mainly two methods commonly used to synthesize $\mathrm{ZnO}$ hollow microspheres: the thermal evaporation process $^{11}$ and the template hydrothermal method. ${ }^{12-15}$ The thermal evaporation process generally involves the vaporization of $\mathrm{Zn}$ powder, solidification of the $\mathrm{Zn}$ liquid droplets, oxidation of spherical $\mathrm{Zn}$ particle surfaces, and sublimation of $\mathrm{Zn}$ within particles. The thermal evaporation technique usually faces disadvantages related to requiring special equipment, high temperatures (typically $>500{ }^{\circ} \mathrm{C}$ ), and vacuum conditions. Besides the thermal evaporation process, another approach for preparation of $\mathrm{ZnO}$ hollow microspheres is the hydrothermal method, which can overcome the aforementioned problems. However, it usually depends on templates such as spherobacterium, sulfonated polystyrene, Pickering emulsion, etc. ${ }^{12-15}$ This template-dependent hydrothermal method always requires extremely complicated synthetic procedures (fabrication of templates, introduction of surface functional groups, deposition of target material, and post removal of the templates). ${ }^{16}$

* Corresponding author.Fax: +86-21-54743242.E-mail: wzshen@sjtu.edu.cn.
Consequently, the use of a template results in high cost, low product yield, and a time-consuming synthesis process. All of these reasons strongly suggest that this template-directed hydrothermal approach is not suitable to be used in large-scale applications. ${ }^{16,17}$ Therefore, further development of a facile, low temperature and template-free synthetic method is quite necessary. However, the direct fabrication of $\mathrm{ZnO}$ hollow microspheres at low-temperature remains a significant challenge. The difficulty lies in the fact that the spherical $\mathrm{ZnO}$ structure is not easily obtained without the help of a spherical template owing to different growth rates of $\mathrm{ZnO}$ crystal in various directions. ${ }^{18}$

In this article, we demonstrate a template-free hydrothermal method to synthesize large-scale $\mathrm{ZnO}$ hollow microspheres. The key points of the successful realization are that we use a high concentration of trisodium citrate to control the nucleation and growth rate of $\mathrm{ZnO}$ crystal for producing solid microspheres with core/shell structures and then remove subsequently the cores by dissolving in a solution of $\mathrm{pH} 8$. Compared with the conventional methods, the present synthetic procedure has the advantages of simplicity (without any special equipments or templates), low growth temperature $\left(85^{\circ} \mathrm{C}\right)$, high yield (the morphological yield is nearly $100 \%$ ), and efficiency (the total growth time is approximately $120 \mathrm{~min}$ ).

\section{Experimental Details}

Synthesis of Core/Shell Structured Microspheres. The hydrothermal reaction solution for the synthesis of core/shell structured microspheres was prepared from aqueous solution containing $25 \mathrm{mM} \mathrm{Zn}\left(\mathrm{NO}_{3}\right)_{2} \cdot 6 \mathrm{H}_{2} \mathrm{O}, 25 \mathrm{mM} \mathrm{C}_{6} \mathrm{H}_{12} \mathrm{~N}_{4}$, and 6.8 $m M \mathrm{C}_{6} \mathrm{H}_{5} \mathrm{Na}_{3} \mathrm{O}_{7} \cdot 2 \mathrm{H}_{2} \mathrm{O}$. After the clear solution was removed to a Pyrex glass bottle (the total volume of the reaction mixture was $40 \mathrm{~mL}$ ), silicon substrates were put into the solution. After being sealed, the bottle was heated at $85^{\circ} \mathrm{C}$ for about $60 \mathrm{~min}$ in a conventional laboratory oven. Subsequently, the product deposited on the silicon substrates was used for the next step of the reaction without any further treatment. 

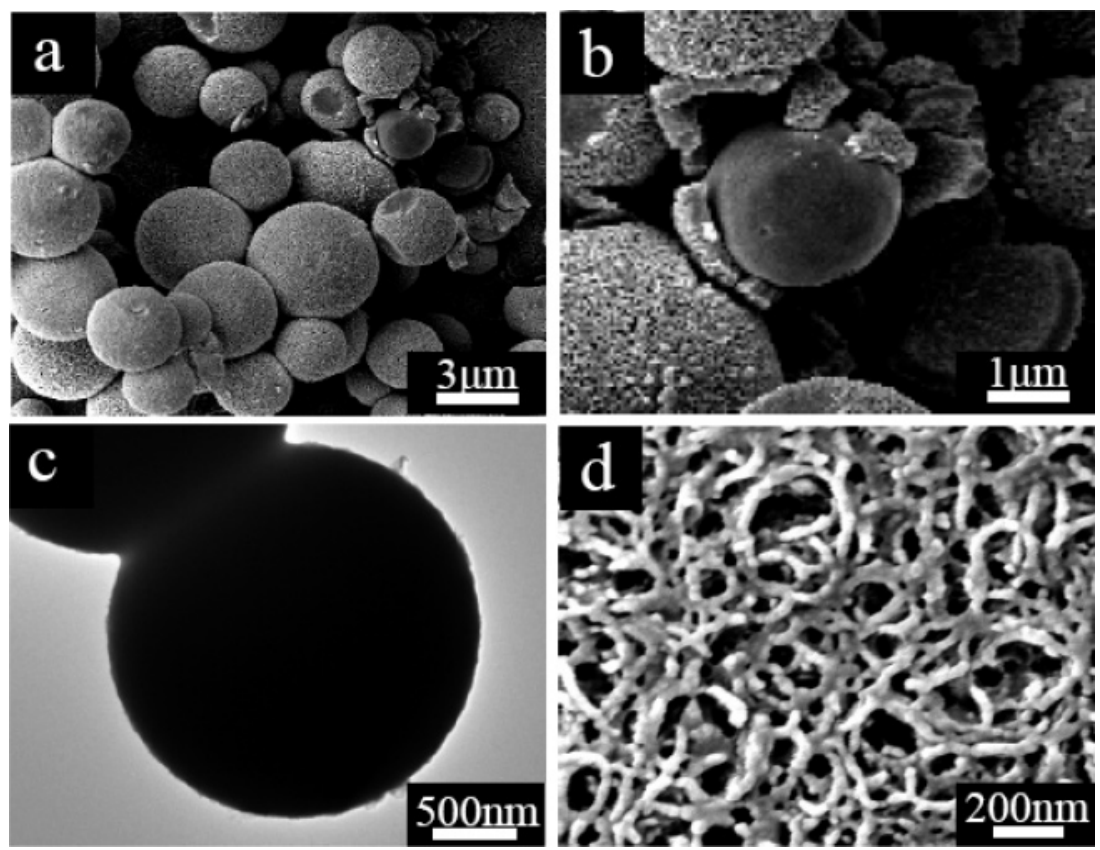

Figure 1. (a and b) FE-SEM images of microspheres. (c) TEM image of a single microsphere. (d) high-magnification FE-SEM image of the microsphere surface.
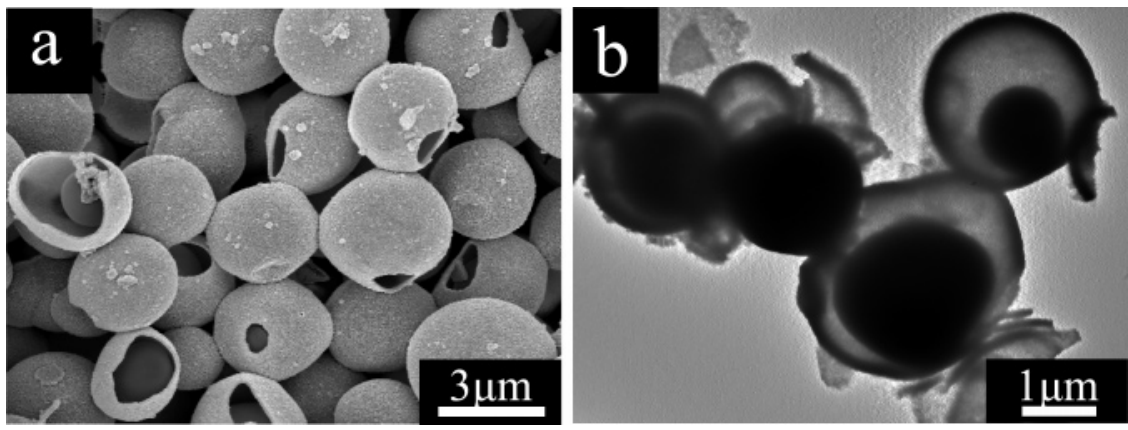

Figure 2. (a) FE-SEM and (b) TEM images of microspheres with core/shell structure. The cores in the microspheres have been partially dissolved in alkaline solution with $\mathrm{pH} 8$.

Synthesis of ZnO Semiconductor Hollow Microspheres. The silicon substrates with product on them were transferred

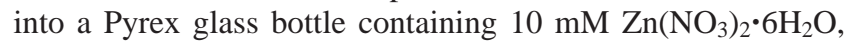
$10 \mathrm{mM} \mathrm{C}_{6} \mathrm{H}_{12} \mathrm{~N}_{4}$, and $2.7 \mathrm{mM} \mathrm{C}_{6} \mathrm{H}_{5} \mathrm{Na}_{3} \mathrm{O}_{7} \cdot 2 \mathrm{H}_{2} \mathrm{O}$. The pH of the solution was adjusted to about 8 by adding drops of ammonia. After being sealed, the bottle was heated at $85{ }^{\circ} \mathrm{C}$ again for another 15 to $60 \mathrm{~min}$. The final product on the $\mathrm{Si}$ substrates was washed with deionized water repeatedly to remove any residual chemical salts and then dried under air atmosphere for characterization.

Series of Controlled Experiments. In order to demonstrate the important role of trisodium citrate used in step 1, we carry out the reaction in a solution containing $25 \mathrm{mM} \mathrm{Zn}\left(\mathrm{NO}_{3}\right)_{2} \cdot 6 \mathrm{H}_{2} \mathrm{O}$ and $25 \mathrm{mM} \mathrm{C}_{6} \mathrm{H}_{12} \mathrm{~N}_{4}$ at $85{ }^{\circ} \mathrm{C}$ for $60 \mathrm{~min}$. During step 2, to illustrate the importance of a solution with proper $\mathrm{pH}$ values, the solid microspheres with core/shell structure prepared by step 1 were also transferred into a solution made up of $10 \mathrm{mM} \mathrm{Zn-}$ $\left(\mathrm{NO}_{3}\right)_{2} \cdot 6 \mathrm{H}_{2} \mathrm{O}, 10 \mathrm{mM} \mathrm{C} \mathrm{H}_{12} \mathrm{~N}_{4}$, and $2.7 \mathrm{mM} \mathrm{C}_{6} \mathrm{H}_{5} \mathrm{Na}_{3} \mathrm{O}_{7} \cdot 2 \mathrm{H}_{2} \mathrm{O}$ with $\mathrm{pH} 11$. To reveal the function of $\mathrm{Zn}\left(\mathrm{NO}_{3}\right)_{2} \cdot 6 \mathrm{H}_{2} \mathrm{O}, \mathrm{C}_{6} \mathrm{H}_{12} \mathrm{~N}_{4}$, and $\mathrm{C}_{6} \mathrm{H}_{5} \mathrm{Na}_{3} \mathrm{O}_{7} \cdot 2 \mathrm{H}_{2} \mathrm{O}$ used in step 2 , the cores were directly removed in dilute ammonia without the aforementioned three reactants (with $\mathrm{pH}$ still kept at 8 ).

Characterization of the Samples. The morphology and structure of the samples were characterized using a fieldemission scanning electron microscope (FE-SEM; Philips XL30FEG) with an accelerating voltage of $5 \mathrm{kV}$ and a high- resolution transmission electron microscope (HRTEM; JEOL JEM-2100F). The selected area electron diffraction (SAED) and energy-dispersive X-ray (EDX) microanalysis of the samples were also performed during transmission electron microscope (TEM) measurements. The room-temperature infrared absorption spectra of the $\mathrm{ZnO}$ microspheres were carried out on a Nicolet Nexus 870 Fourier transform infrared spectrometer. Raman and photoluminescence (PL) spectra were recorded at room temperature by a Jobin Yvon LabRAM HR 800UV micro-Raman/ PL system under an $\mathrm{Ar}^{+}(514.5 \mathrm{~nm})$ and $\mathrm{He}-\mathrm{Cd}(325.0 \mathrm{~nm})$ laser excitation, respectively.

\section{Results and Discussion}

In our experiments, solid microspheres with core/shell structures were first prepared by a hydrothermal process. Figure 1, panels a and b, shows the FE-SEM images of the as-prepared microspheres. From Figure 1a, it is obvious that large-scale microspheres can be obtained. The broken microsphere presented in Figure 1b indicates that the as-prepared microsphere has a core in it forming the core/shell microstructure. The corresponding TEM image depicted in Figure 1c also demonstrates that the as-prepared microspheres are solid with cores inside. To further describe the surface structure of these microspheres, we show in Figure 1d the high-magnification FESEM image. The figure illustrates a porous microsphere shell, 

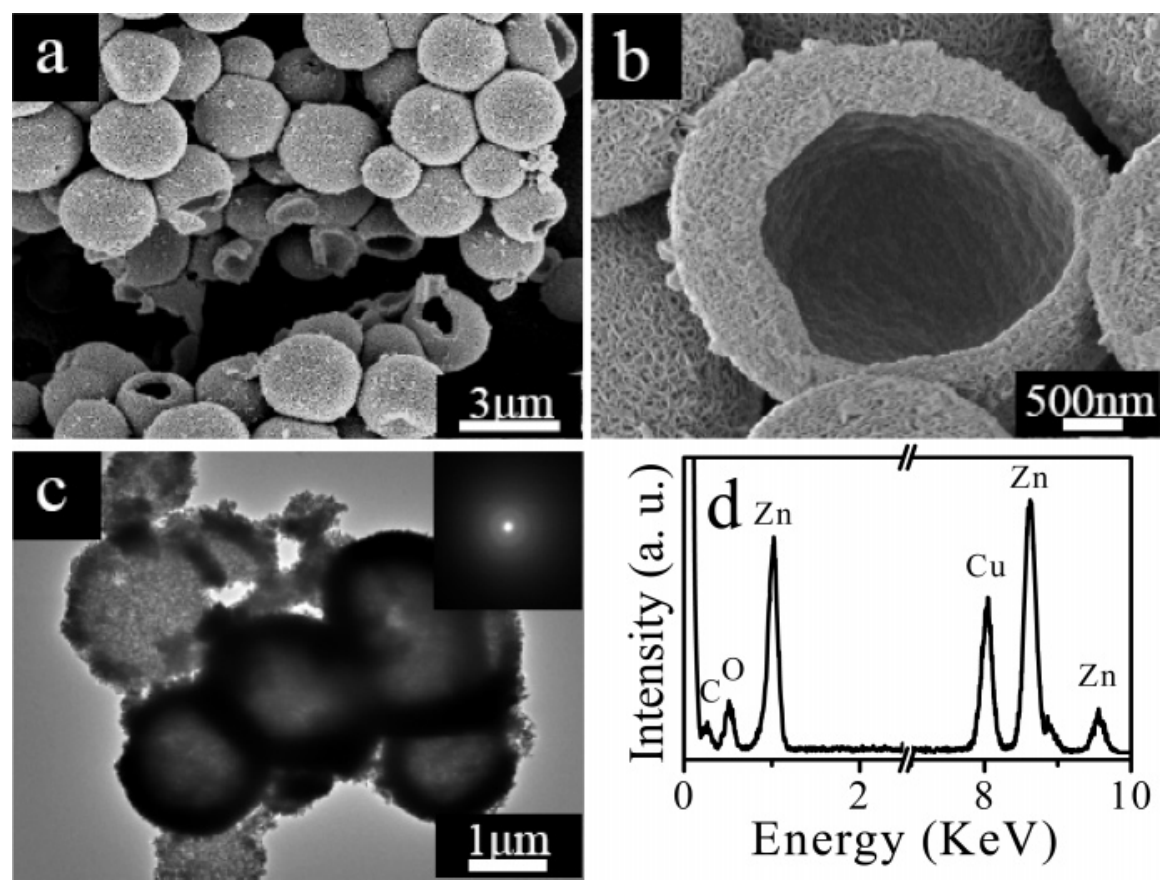

Figure 3. (a) Low- and (b) high-magnification FE-SEM images of hollow microspheres. (c) TEM image of hollow microspheres, with the selected area electron diffraction pattern shown in the inset. (d) EDX spectrum of the corresponding sample.

which is made up of a network of flexible nanowires bent and connected with each other. The thicknesses of these nanowires mostly range between 20 and $60 \mathrm{~nm}$.

The hollow microspheres are obtained subsequently by removing the cores without affecting the spherical structure of the shells. Our strategy is to transfer the as-prepared sample into a bottle containing a solution at $\mathrm{pH} 8$ with the other reactants almost unchanged (see Experimental section). Figure 2a displays the morphology of the sample treated in this solution for $15 \mathrm{~min}$, from which we can see that some of the shells have a partially opened mouth on them. These broken microspheres clearly indicate that the cores in the microspheres have been partially dissolved. The TEM observation [Figure 2b] also proves that there are hollow interior spaces between the cores and the shells, likely due to partial dissolution of cores under relatively high $\mathrm{pH}$ condition.

When the reaction time increased to $60 \mathrm{~min}$, all of the cores in the microspheres were removed. The FE-SEM images are shown in Figure 3, panels a and b. The hollow nature of the microsphere is clearly depicted via the partially opened microspheres [Figure 3b]. Although some of the microspheres are "closed", further evidence for the hollow structure can be found from the TEM image. As demonstrated in Figure 3c, there is a strong contrast difference in all of the microspheres with a light inner center and relative dark edge, confirming that the obtained microspheres are hollow. The SAED pattern of a hollow microsphere displayed in the inset of Figure $3 \mathrm{c}$ reveals the amorphous nature of these microspheres, which is also confirmed by X-ray diffraction (XRD) observation. During the TEM measurements, EDX spectroscopy analysis has also been performed. The result, shown in Figure 3d, indicates that the hollow microspheres are mostly composed of $\mathrm{Zn}$ and $\mathrm{O}$ elements. The signal of $\mathrm{Cu}$ originates from the copper grid, whereas the $\mathrm{C}$ peak should come from carbon film on the $\mathrm{Cu}$ grid and impurity groups in the as-prepared microspheres, which will be discussed in the infrared absorption later.

Based on the above experimental observation, we suggest that the whole synthetic process can be divided into the following two steps. Step 1: Prepare solid microspheres with core/shell structure. Step 2: Remove the cores by treating the obtained microspheres in a solution with $\mathrm{pH} 8$. Figure 4 outlines the possible formation mechanism of $\mathrm{ZnO}$ hollow microspheres by the schematic diagrams and the corresponding FE-SEM images. We believe that the following reactions are involved in the step 1 for the formation of solid microspheres with core/ shell structure:

$$
\begin{gathered}
\mathrm{C}_{6} \mathrm{H}_{12} \mathrm{~N}_{4}+6 \mathrm{H}_{2} \mathrm{O} \rightarrow 6 \mathrm{HCHO}+4 \mathrm{NH}_{3} \\
\mathrm{NH}_{3}+\mathrm{H}_{2} \mathrm{O} \leftrightarrow \mathrm{NH}_{4}^{+}+\mathrm{OH}^{-} \\
\mathrm{Zn}^{2+}+2 \mathrm{OH}^{-} \leftrightarrow \mathrm{Zn}(\mathrm{OH})_{2} \\
\mathrm{Zn}(\mathrm{OH})_{2} \leftrightarrow \mathrm{ZnO}+\mathrm{H}_{2} \mathrm{O}
\end{gathered}
$$

During the hydrothermal process, the role of methenamine $\left(\mathrm{C}_{6} \mathrm{H}_{12} \mathrm{~N}_{4}\right)$ in the growth of solid microspheres can be viewed as a $\mathrm{pH}$ buffer by slowly releasing $\mathrm{OH}^{-}$ions through thermal decomposition [eqs 1 and 2]. ${ }^{19}$ In this process, $\mathrm{OH}^{-}$ions react with $\mathrm{Zn}^{2+}$ ions to form $\mathrm{Zn}(\mathrm{OH})_{2}$ nanoclusters in solution [eq 3 ], as shown in the schematic diagram of Figure 4a. It is wellknown that trisodium citrate $\left(\mathrm{C}_{6} \mathrm{H}_{5} \mathrm{Na}_{3} \mathrm{O}_{7} \cdot 2 \mathrm{H}_{2} \mathrm{O}\right)$ will not react with any compound in our reaction system; however, if the solution does not contain trisodium citrate, $\mathrm{ZnO}$ nanorod growth will be realized by a dissolution-reprecipitation mechanism. ${ }^{19}$ A previous study has demonstrated that encapsulation of crystallization additives in solution can be used to control the nucleation and growth rate of crystals. ${ }^{20}$ Tian et al., ${ }^{21}$ have reported that a very small quantity of citrate ions slow crystal growth along the $<001>$ orientation, providing us a simple approach to control the aspect ratio (length to width) of the $\mathrm{ZnO}$ nanorods.

We have employed a high concentration of citrate ions to reduce significantly the nucleation and growth rate of $\mathrm{ZnO}$ crystal in all directions. As a result, $\mathrm{Zn}(\mathrm{OH})_{2}$ solid microspheres are expected to be yielded [Figure $4 \mathrm{~b}$ ]. When the reaction time increases, $\mathrm{ZnO}$ nanowires began to form on the surface of $\mathrm{Zn}$ $(\mathrm{OH})_{2}$ solid microspheres via a process that involves dissolution 


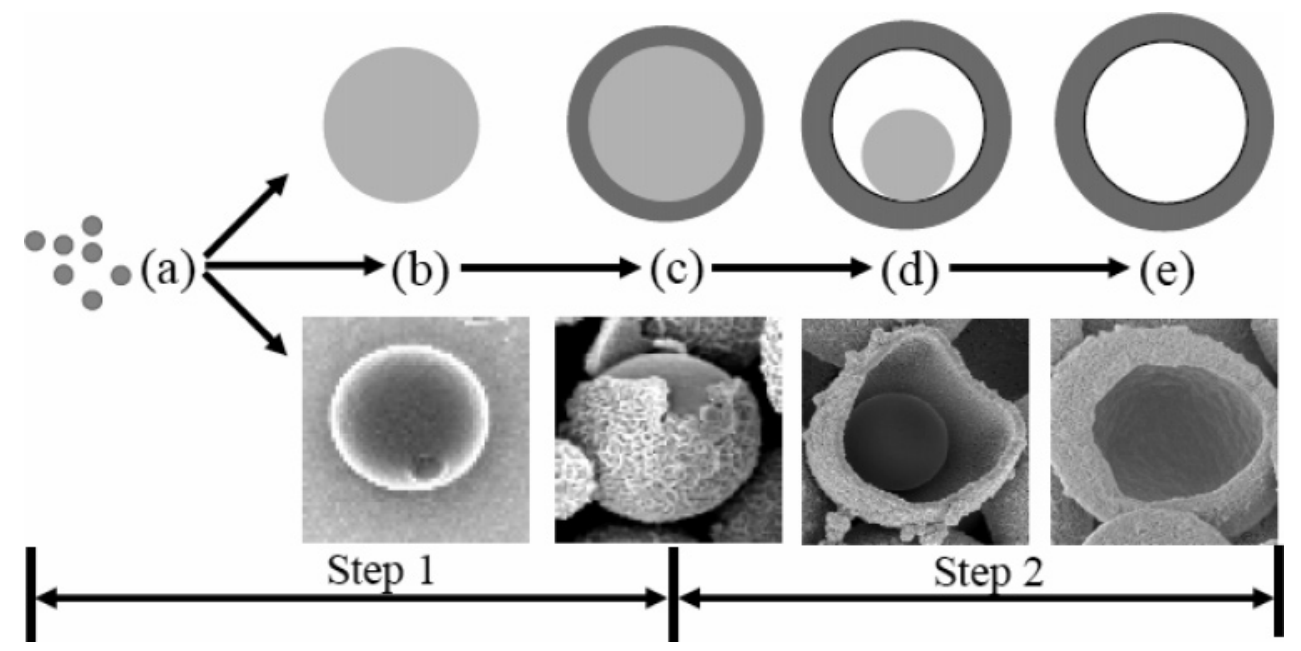

Figure 4. Schematic illustration of the formation process of $\mathrm{ZnO}$ hollow microspheres, together with the corresponding FE-SEM images. (a) Formation of $\mathrm{Zn}(\mathrm{OH})_{2}$ nanoclusters in solution. (b) Synthesis of solid microspheres. (c) Formation of microspheres with core/shell structure. (d) Partial dissolution of the cores in alkaline solution. e) Formation of Znhollow microspheres.
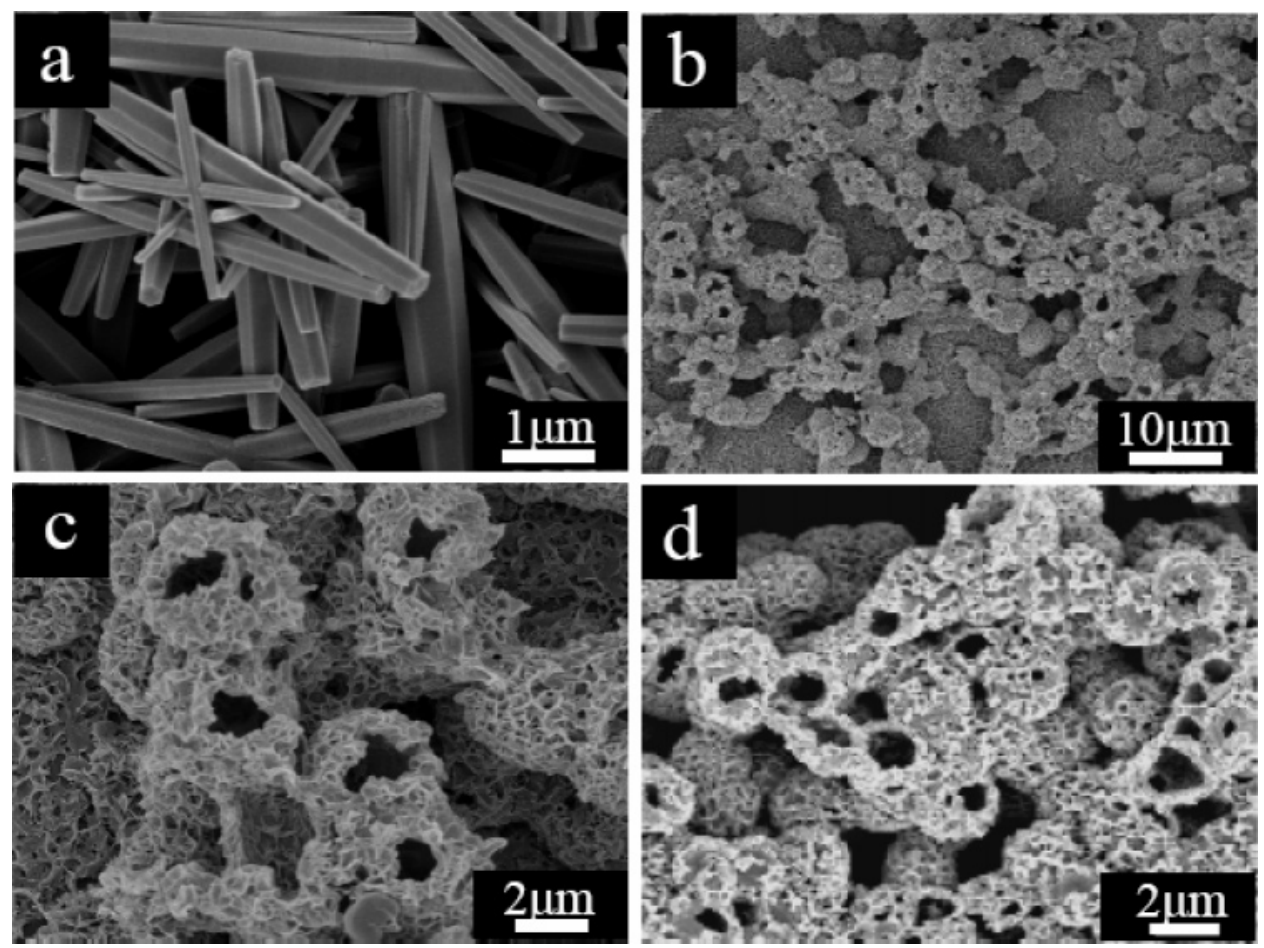

Figure 5. (a) FE-SEM image of ZnO nanorods grown in a solution without trisodium citrate. (b) Low- and (c) high-magnification FE-SEM images of hollow microspheres by treating the solid microspheres in a solution with $\mathrm{pH}$ 11. (d) FE-SEM images of hollow microspheres by removing the cores in dilute ammonia at $\mathrm{pH} 8$.

of $\mathrm{Zn}(\mathrm{OH})_{2}$ and formation of $\mathrm{ZnO}$ by precipitation from solution [eq 4].22 These $\mathrm{ZnO}$ nanowires bend and connect with each other on the surface of $\mathrm{Zn}(\mathrm{OH})_{2}$ cores forming $\mathrm{ZnO}$ shells, leading to the formation of solid microspheres with a core/shell structure [a broken microsphere shown in Figure 4c clearly depicts the core/shell structure].

In the following step (step 2), the solid microspheres with the core/shell structure were transferred into a solution with $\mathrm{pH}$ 8 (the $\mathrm{pH}$ of this solution was adjusted by adding a few drops of ammonia). The role of the added ammonia is to dissolve $\mathrm{Zn}(\mathrm{OH})_{2}$ cores in the microspheres, which can be described by the following chemical reaction: ${ }^{23}$

$$
\mathrm{Zn}(\mathrm{OH})_{2}+4 \mathrm{NH}_{3}=\left(\mathrm{Zn}\left(\mathrm{NH}_{3}\right)_{4}\right)^{2+}+2 \mathrm{OH}^{-}
$$

This method was found to effectively remove $\mathrm{Zn}(\mathrm{OH})_{2}$ cores in a short time without destroying $\mathrm{ZnO}$ shells in the alkaline solution. Figure $4 \mathrm{~d}$ reveals a microsphere with partially dissolved core. Although loss of $\mathrm{ZnO}$ shells in the alkaline solution also occurs due to the slight solubility of $\mathrm{ZnO}$ in the solution containing a small amount of ammonia, ${ }^{24}$ the newly synthesized $\mathrm{ZnO}$ grown on the shells can compensate for the loss [we will further demonstrate this in Figure 5d later]. Therefore, the synthesis of hollow $\mathrm{ZnO}$ microspheres is achieved without affecting the spherical structure of the microsphere shells [Figure $4 \mathrm{e}]$.

As for the reaction time, it is found that the process for the formation of the solid microspheres with the core/shell structure during the first step usually takes $60 \mathrm{~min}$. During the second 


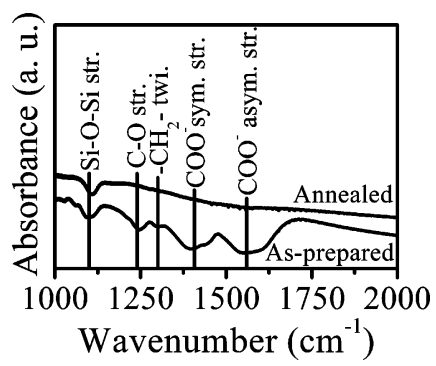

Figure 6. Room-temperature infrared absorption spectra of the asprepared and the annealed $\mathrm{ZnO}$ microspheres.

step, the cores are removed by treating the as-prepared solid microspheres in a solution with $\mathrm{pH}$ 8. This treatment takes up another $60 \mathrm{~min}$ for complete removal of the cores. The total time required for the realization of $\mathrm{ZnO}$ hollow microspheres is approximately $120 \mathrm{~min}$. In addition, as demonstrated in Figure $3 \mathrm{a}$, there are no other structures being synthesized apart from $\mathrm{ZnO}$ microspheres, indicating a nearly $100 \%$ morphological yield of the spherical structure. Therefore, the present method provides a simple and efficient way to produce large-scale $\mathrm{ZnO}$ hollow microspheres.

We have carried out a series of controlled experiments to better understand the formation mechanism of $\mathrm{ZnO}$ hollow microspheres. To demonstrate the important role of trisodium citrate during step 1 for preparing solid microspheres with core/ shell structures, we perform the reaction in the absence of trisodium citrate with the other conditions kept the same. Figure 5a displays the yielded hexagonal-structured $\mathrm{ZnO}$ nanorods due to the fastest growth $<001>$ orientation of the $\mathrm{ZnO}$ crystal. If a very small quantity of trisodium citrate was added, the citrate ions would strongly bind to the $\mathrm{Zn}$ atoms on the (001) surface, limiting the growth rate of the $<001>$ orientation. In this case, $\mathrm{ZnO}$ nanorods will become shorter and fatter. ${ }^{21} \mathrm{~A}$ high concentration of trisodium citrate will slow down significantly the nucleation and growth rate of $\mathrm{ZnO}$ crystals in all directions, resulting in the formation of spherical structure [Figure 1a]. Therefore, a large enough amount of trisodium citrate is very important to realize the solid microspheres.

During step 2, for removing the cores from the core/shell structured microspheres, we have found that it is very important to employ a solution with a proper $\mathrm{pH}$ value. When the specimens were put into the solution with a higher $\mathrm{pH}(11$, with the concentration of the other reactants kept the same), not only the cores but also the shells were dissolved. This is because the solubilities of $\mathrm{Zn}(\mathrm{OH})_{2}$ and $\mathrm{ZnO}$ are reported to increase with $\mathrm{pH}^{22}$ Figure $5 \mathrm{~b}$ shows a typical FE-SEM image of the sample treated in an alkaline solution having a $\mathrm{pH}$ of about 11 for $30 \mathrm{~min}$. Figure 5c is a high-magnification FE-SEM image. It is clear that most of the hollow microsphere shells have been damaged due to the dissolution of shells.

Besides the $\mathrm{pH}$ value, a certain amount of zinc nitrate hexahydrate $\left(\mathrm{Zn}\left(\mathrm{NO}_{3}\right)_{2} \cdot 6 \mathrm{H}_{2} \mathrm{O}\right), \mathrm{C}_{6} \mathrm{H}_{12} \mathrm{~N}_{4}$, and $\mathrm{C}_{6} \mathrm{H}_{5} \mathrm{Na}_{3} \mathrm{O}_{7} \cdot 2 \mathrm{H}_{2} \mathrm{O}$ in the solution also plays an important role during the removal process of the cores. Figure $5 d$ presents the result of removing the cores in dilute ammonia $(\mathrm{pH} 8)$ without the aforementioned three reactants. In comparison with Figure 3a, although the cores in microspheres disappear, the shells have also been destroyed because of the slight solubility of $\mathrm{ZnO}$ in dilute ammonia. This observation indicates the necessity of $\mathrm{Zn}\left(\mathrm{NO}_{3}\right)_{2} \cdot 6 \mathrm{H}_{2} \mathrm{O}, \mathrm{C}_{6} \mathrm{H}_{12} \mathrm{~N}_{4}$, and $\mathrm{C}_{6} \mathrm{H}_{5} \mathrm{Na}_{3} \mathrm{O}_{7} \cdot 2 \mathrm{H}_{2} \mathrm{O}$ in the solution. The function of the added reactants is to grow $\mathrm{ZnO}$ on spherical shells during the process of removing the cores. The newly synthesized $\mathrm{ZnO}$ can compensate for the slight loss in the alkaline solution, protecting the $\mathrm{ZnO}$ shells from being damaged.

As pointed out above, we have employed a high concentration of trisodium citrate in our reaction system to control the nucleation and growth rate of $\mathrm{ZnO}$ crystal. Therefore, the citric
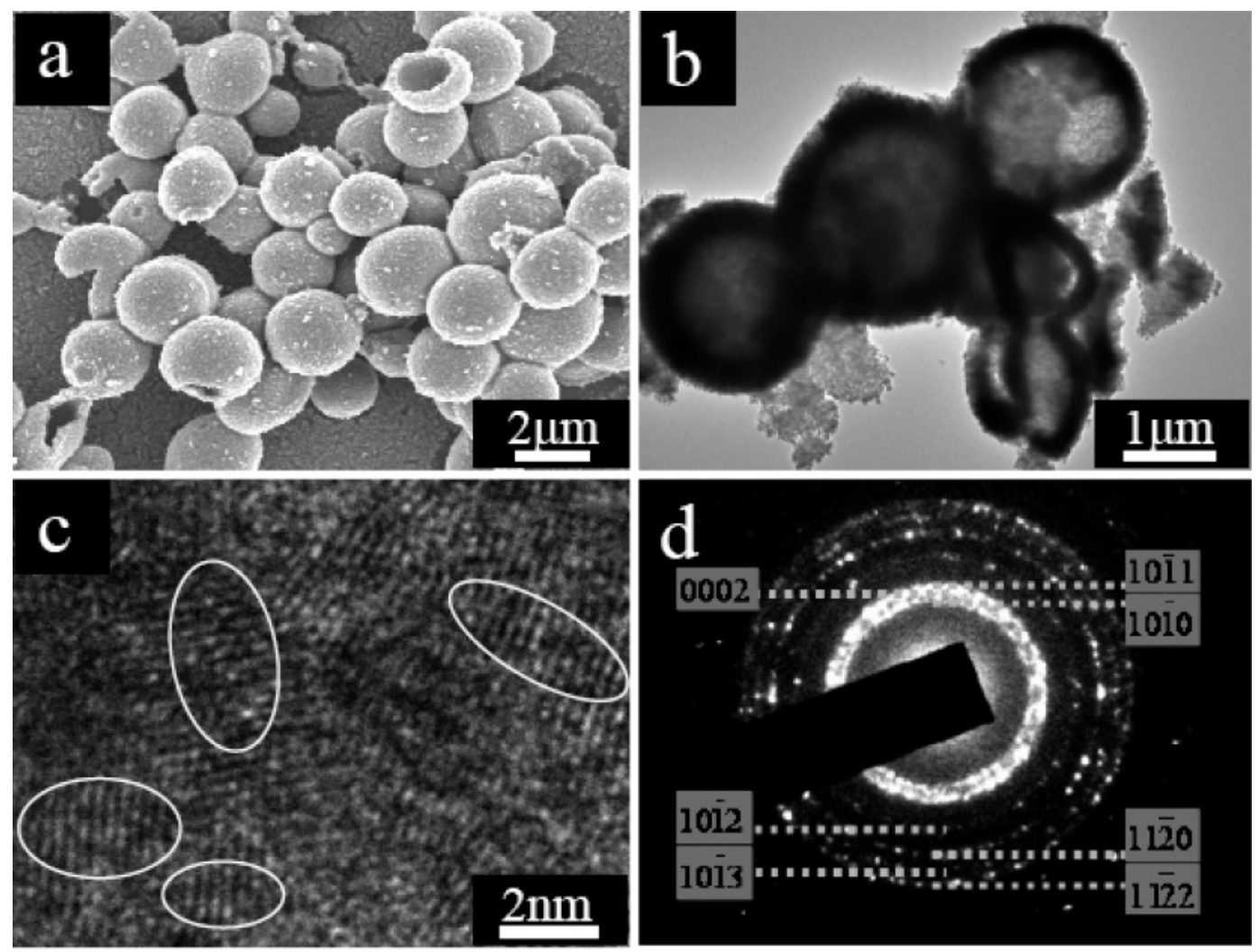

Figure 7. (a) FE-SEM and (b) TEM images of the annealed $\mathrm{ZnO}$ hollow microspheres. (c) HR-TEM image of an annealed $\mathrm{ZnO}$ hollow microsphere shell. (d) Selected area electron diffraction pattern of an annealed $\mathrm{ZnO}$ hollow microsphere. 
acid ions may form impurity groups in the as-prepared microspheres. To gain more information about the composition of the as-prepared $\mathrm{ZnO}$ hollow microspheres, we have further carried out Fourier transform infrared absorption analysis. Figure 6 displays the room-temperature infrared absorption spectrum of the as-prepared $\mathrm{ZnO}$ microspheres. Such a spectrum can be used to identify the functional groups presented in the prepared samples. In the citrate groups,

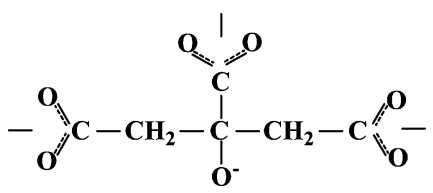

$\mathrm{C}=\mathrm{O}$ and $\mathrm{C}-\mathrm{O}$ bonds with the same $\mathrm{C}$ atom will average into two equivalent carbon-oxygen bonds:

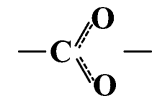

The strong coupling between the two equal bonds results in the $\mathrm{COO}^{-}$asymmetrical stretching vibration (asym. str.) from 1558 to $1593 \mathrm{~cm}^{-1}$ and relatively weak $\mathrm{COO}^{-}$symmetrical stretching vibration (sym. str.) from 1403 to $1455 \mathrm{~cm}^{-1} .^{25,26}$ Therefore, the absorption bands of the as-prepared sample located at $\sim 1570$ and $\sim 1420 \mathrm{~cm}^{-1}$ can be attributed to the $\mathrm{COO}^{-}$asymmetric and symmetric stretching vibration modes, respectively. In addition, the band at $1240 \mathrm{~cm}^{-1}$ is due to $\mathrm{C}-\mathrm{O}$ stretching (str.) vibration, whereas another band appearing at $1300 \mathrm{~cm}^{-1}$ can be ascribed to the twisting (twi.) mode of the methylene groups. ${ }^{27}$ These results reveal that the as-prepared microspheres do contain citrate impurities. The infrared absorption spectrum further indicates that, as mentioned above, the $\mathrm{C}$ peak observed in EDX [Figure 3d] partially originates from the citrate impurities.

Generally speaking, annealing can decompose impurity groups in the sample and improve the crystal quality. Thermal treatment of the as-prepared $\mathrm{ZnO}$ microspheres was performed at $400{ }^{\circ} \mathrm{C}$ under an air atmosphere for $120 \mathrm{~min}$. Figure 6 also shows the room-temperature infrared absorption spectrum of the annealed $\mathrm{ZnO}$ microspheres. Except for the absorption peak at around $1100 \mathrm{~cm}^{-1}$ due to the stretching vibrations of $\mathrm{Si}-$ $\mathrm{O}-\mathrm{Si}$ in the oxidized $\mathrm{Si}$ substrate, ${ }^{28}$ all of the absorption bands corresponding to the citrate impurities disappear, clearly demonstrating that the impurities have been removed.

The morphology and crystal structure of the annealed $\mathrm{ZnO}$ microspheres have also been investigated by FE-SEM and TEM. Compared with the morphology of the as-prepared sample in Figure 3a, no significant changes were observed in the FE-SEM image of the annealed one presented in Figure 7a. The corresponding TEM image shown in Figure $7 \mathrm{~b}$ indicates that the hollow structure of the microspheres is still retained after annealing. HRTEM observation can give further insight into the structural features of the $\mathrm{ZnO}$ microspheres. The result is illustrated in Figure 7c, which indicates that the annealed $\mathrm{ZnO}$ microspheres are polycrystalline. The corresponding ring-like SAED pattern [Figure 7d] also suggests that the annealed microspheres are polycrystalline and the diffraction rings from inside to outside can be indexed to (1010), (0002), (1011), $(10 \overline{1} 2),(1 \overline{1} \overline{2}),(10 \overline{1} 3)$, and $(11 \overline{2} 2)$ planes of the wurtzite $\mathrm{ZnO}$, respectively. ${ }^{11 \text { a }}$ In addition, our XRD observation is consistent with the above TEM results, with the strong (002), (100), and (101) diffraction peaks and weak (102), (110), (103), and (112) ones.

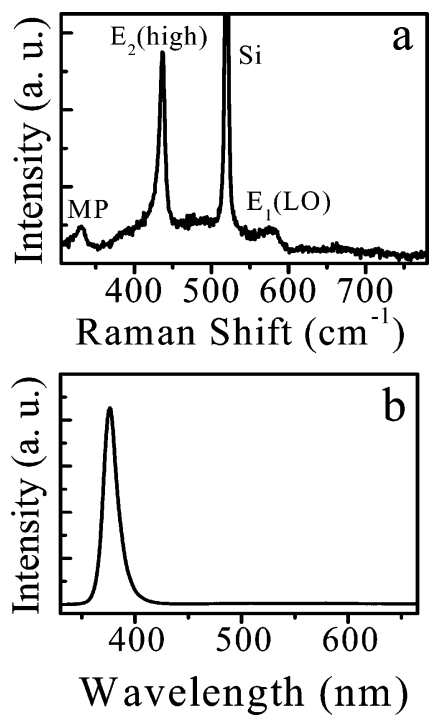

Figure 8. Room-temperature (a) Raman and (b) PL spectra of the annealed $\mathrm{ZnO}$ hollow microspheres.

The crystallization degree of the annealed $\mathrm{ZnO}$ microspheres can further be evaluated by room-temperature Raman spectra. As shown in Figure 8a, the remarkable nonpolar optical phonon $\mathrm{E}_{2}$ (high) mode of $\mathrm{ZnO}$ is located at $437 \mathrm{~cm}^{-1}$, which is a typical Raman active branch of wurtzite $\mathrm{ZnO}$. In addition to the 520 $\mathrm{cm}^{-1}$ structure from the Si substrate, the other two weak peaks at 332 and $581 \mathrm{~cm}^{-1}$ correspond well to the $\mathrm{ZnO}$ multiplephonon (MP) scattering process and $\mathrm{E}_{1}$ [longitudinal-optical (LO)] mode, respectively. ${ }^{29,30}$ The appearance of the characteristic Raman peaks demonstrates that the annealed $\mathrm{ZnO}$ microspheres are of a good crystalline wurtzite structure, which is consistent with the HRTEM observation.

Finally, we perform room-temperature PL spectroscopy to explore the optical properties and the crystal quality of the annealed $\mathrm{ZnO}$ microspheres. From Figure 8b, it is clear that the PL spectrum has a strong ultraviolet (UV) peak at $376 \mathrm{~nm}$ and a negligible green band. The UV emission originates from the recombination of free excitons in the near-band-edge of the wide band gap $\mathrm{ZnO}$. Although the origin of the broad visible luminescence is still controversal due to its complexity, it is generally believed that the green emission comes from the recombination of a photogenerated hole with the singly ionized oxygen vacancy. ${ }^{31}$ The strong narrow UV peak and the negligible green band in the PL spectrum indicate the high optical quality of the annealed $\mathrm{ZnO}$ microspheres. It should be noted that the previous reports reveal that the $\mathrm{ZnO}$ hollow microspheres prepared through the conventional methods contain a large number of oxygen vacancies resulting in a weak UV emission and a strong broad green emission. ${ }^{11 \mathrm{~b}-11 \mathrm{e}}$ The above $\mathrm{PL}$ observation demonstrates that the $\mathrm{ZnO}$ microspheres obtained through the present method possess high optical quality with low oxygen vacancies. Therefore, these $\mathrm{ZnO}$ microspheres may be applicable for the fabrication of optoelectronic devices such as ultraviolet light-emitting diodes and diode lasers.

\section{Conclusions}

In summary, we have developed a simple, low temperature, efficient, environmentally benign, hydrothermal method to realize the large-scale $\mathrm{ZnO}$ hollow microspheres. Based on the morphology evolution of $\mathrm{ZnO}$ microspheres observed by SEM and TEM during the growth process, a possible formation mechanism is proposed. In the first step, microspheres with a core/shell structure were prepared via a hydrothermal synthesis 
approach, in which a high concentration of citrate ions was used to control $\mathrm{ZnO}$ nucleation and growth. The experimental results demonstrated that a certain concentration of trisodium citrate played a key role in the formation of microspheres with a core/ shell structure. In the absence of trisodium citrate, only hexagonally structured $\mathrm{ZnO}$ nanorods were obtained. In the second step, the cores were removed by treating the as-obtained core/shell structured microspheres in an alkaline solution with $\mathrm{pH}$ 8. During this process, an alkaline environment with proper $\mathrm{pH}$ is also crucial to form $\mathrm{ZnO}$ hollow microspheres. If the $\mathrm{pH}$ is too high, the shells of the microspheres will be damaged due to the increasing solubility of $\mathrm{ZnO}$ with $\mathrm{pH}$. The infrared absorption spectra indicate that annealing can lead to decompose impurity groups in the as-prepared samples. Raman results demonstrate that the annealed $\mathrm{ZnO}$ microspheres are of good crystalline wurtzite structure. The room-temperature PL spectrum of the annealed microspheres shows a strong UV emission, together with a negligible green band emission. These $\mathrm{ZnO}$ hollow microspheres may find potential applications in photocatalysis, photonic crystals and advanced optoelectronic devices. The unique method presented in this paper may also provide a new strategy to design and organize other hollow structured materials.

Acknowledgment. This work was supported by the Natural Science Foundation of China (Contract Nos. 10674094 and 10734020), National Major Basic Research Project of 2006CB921507, the Minister of Education of PCSIRT (Contract No. IRT0524), and the Shanghai Municipal Commission of Science and Technology Projects of 05QMH1411, 05DJ14003, and 06JC14039.

\section{References and Notes}

(1) Ding, G. Q.; Shen, W. Z.; Zheng, M. J.; Fan, D. H. Appl. Phys. Lett. 2006, 88, 103106.

(2) (a) Wang, X. D.; Summers, C. J.; Wang, Z. L. Nano Lett. 2004, 4, 423. (b) Huang, M. H.; Wu, Y. Y.; Feick, H.; Tran, N.; Weber, E.; Yang, P. D. Adv. Mater. 2001, 13, 113. (c) Wang, Z. L. J. Mater. Chem. 2005 , $15,1021$.

(3) Vayssieres, L.; Keis, K.; Hagfeldt, A.; Lindquist, S. E. Chem. Mater. 2001, 13, 4395.

(4) (a) Lao, J. Y.; Huang, J. Y.; Wang, D. Z.; Ren, Z. F. Nano Lett. 2003, 3, 235. (b) Guo, P. X.; Wang, Z. L. Appl. Phys. Lett. 2003, 84, 2883.

(5) Xu, W. L.; Zheng, M. J.; Ding, G. Q.; Shen, W. Z. Chem. Phys. Lett. 2005, 411, 37.

(6) (a) Zhu, Y. F.; Shi, J. L.; Shen, W. H.; Dong, X. P.; Feng, J. W.; Ruan, M. L.; Li, Y. S. Angew. Chem., Int. Ed. 2005, 44, 5083. (b) Im, S. H.; Jeong, U.; Xia, Y. N. Nat. Mater. 2005, 4, 671. (c) Dinsmore, A. D.; Hsu, M. F.; Nikolaides, M. G.; Marquez, M.; Bausch, A. R.; Weitz1, D. A. Science 2002, 298, 1006. (d) Yang, H. G.; Zeng, H. C. Angew. Chem. Int. Ed. 2004, 43, 5206.

(7) Noble, P. F.; Cayre, O. J.; Alargova, R. G.; Velev, O. D.; Paunov, V. N. J. Am. Chem. Soc. 2004, 126, 8092-8093.
(8) Lou, X. W.; Yuan, C.; Rhoades, E.; Zhang, Q.; Archer, L. A. Adv. Funct. Mater. 2006, 16, 1679.

(9) (a) Guo, L.; Liang, F.; Wen, X.; Yang, S.; He, L.; Zheng, W.; Chen, C.; Zhong, Q. Adv. Funct. Mater. 2007, 17, 425. (b) Jiang, Z. Y.; Xie, Z X.; Zhang, X. H.; Lin, S. C.; Xu, T.; Xie, S. Y.; Huang, R. B.; Zheng, L. S. Adv. Mater. 2004, 16, 904. (c) Liu, Y.; Chu, Y.; Zhuo, Y.; Dong, L.; Li, L.; Li, M. Adv. Funct. Mater. 2007, 17, 933.

(10) (a) Duan, G.; Cai, W.; Luo, Y.; Sun, F. Adv. Funct. Mater. 2007, 17, 644. (b) Deng, Z.; Chen, W. M.; Zhou, S. X.; You, B.; Wu, L. M. Langmuir 2006, 22, 6403. (c) Ohnishi, M.; Kozuka, Y.; Ye, Q. L.; Yoshikawa, H.; Awaga, K.; Matsuno, R.; Kobayashi, M.; Takahara, A.; Yokoyama, T.; Bandow, S.; Iijima, S. d. J. Mater. Chem. 2006, 16, 3215. (d) Yu, X. L.; Cao, C. B.; Zhu, H. S.; Li, Q. S.; Liu, C. L.; Gong, Q. H. Adv. Funct. Mater. 2007, 17, 1397.

(11) (a) Gao, P. X.; Wang, Z. L. J. Am. Chem. Soc. 2003, 125, 11299.

(b) Shen, G. Z.; Bando, Y.; Lee, C. J. J. Phys. Chem. B 2005, 109, 10578.

(c) Lu, H. B.; Liao, L.; Li, J. C.; Wang, D. F.; He, H.; Fu, Q.; Xu, L.; Tian, Y. J. Phys. Chem. B 2006, 110, 23211. (d) Sulieman, K. M.; Huang, X. T.; Liu, J. P.; Tang, M. Nanotechnology 2006, 17, 4950. (e) Zhang, Y.; Zhang, W. F.; Zheng, H. W. Scr. Mater. 2007, 57, 313.

(12) Zhou, H.; Fan, T. X.; Zhang, D. Microporous Mesoporous Mater. 2007, 100, 322

(13) Lipowsky, P.; Hirscher, M.; Hoffmann, R. C.; Bill, J.; Aldinger, F. Nanotechnology 2007, 18, 165603.

(14) Yang, Y.; Chu, Y.; Zhang, Y. P.; Yang, F. Y.; Liu, J. L. J. Solid State Chem. 2006, 179, 470.

(15) He, Y. j. Mater. Lett. 2005, 59, 114

(16) San, H.; Jang, B.; Kim, T.; Oh, S. M.; Hyeon, T. Adv. Funct. Mater. 2005, 15, 1845.

(17) Lou, X. W.; Wang, Y.; Yuan, C.; Lee, J. Y.; Archer, L. A. Adv. Mater. 2006, 18, 2325.

(18) Umar, A.; Hahn, Y. B. Appl. Phys. Lett. 2006, 88, 173120.

(19) Govender, K.; Boyle, D. S.; Kenway, P. B.; O', Brien, P. J. Mater. Chem. 2004, 14, 2575.

(20) Wang, W. S.; Zhen, L.; Xu, C. Y.; Zhang, B. Y.; Shao, W. Z Chem. Mater. 2006, 18, 3557.

(21) Tian, Z. R.; Voigt, J. A.; Liu, J.; Mckenzie, B.; Mcdermott, M. J.; Cygan, R. T.; Criscenti, L. J. Nat. Mater. 2003, 2, 821.

(22) McBride, R. A.; Kelly, J. M.; McCormack, D. E. J. Mater. Chem. 2003, 13, 1196

(23) Ennaoui, A.; Weber, M.; Saad, M.; Harneit, W.; Lux-Steiner, M. C.; Karg, F. Thin Solid Films 2000, 361-362, 450

(24) Ali, H. A.; Iliadis, A. A.; Lee, U. Solid-State Electron. 2004, 48, 2025.

(25) Omura, Y. Spectrosc. Acta Part A 1998, 54, 507.

(26) Mizuguchi, M.; Nara, M.; Kawano, K.; Nitta, K. FEBS Lett. 1997. 417, 153.

(27) Stuart, B. H. Infrared Spectroscopy: Fundamentals and Applications; John Wiley \& Sons, Ltd.: New York, 2004; Chapter 4.

(28) Chen, X. Y.; Shen, W. Z.; Chen, H.; Zhang, R.; He, Y. L. Nanotechnology 2006, 17, 595 .

(29) Cao, B. Q.; Cai, W. P.; Zeng, H. B.; Duan, G. T. J. Appl. Phys. 2006, 99, 073516.

(30) Ashkenov, N.; Mbenkum, B. N.; Bundesmann, C.; Riede, V.; Lorenz, M.; Spemann, D.; Kaidashev, E. M.; Kasic, A.; Schubert, M.; Grundmann, M.; Wagner, G.; Neumann, H.; Darakchieva, V.; Arwin, H.; Monemar, B. J. Appl. Phys. 2003, 93, 126.

(31) Vanheusden, K.; Warren, W. L.; Seager, C. H.; Tallant, D. K.; Voigt, J. A.; Gnade, B. E. J. Appl. Phys. 1996, 79, 7983. 